\title{
Could the wild population of Large Yellow Croaker Larimichthys crocea (Richardson) in China be restored? A case study in Guanjingyang, Fujian, China
}

\author{
Guanqiong Ye ${ }^{1, *}$, Ying Lin ${ }^{1}$, Cuicui Feng ${ }^{1,6}$, Loke Ming Chou ${ }^{2}$, Qutu Jiang ${ }^{1}$, Panpan Ma ${ }^{1}$, \\ Shengyun Yang ${ }^{3}$, Xiaofeng $\mathrm{Shi}^{4}$, Mingru Chen ${ }^{3}$, Xuchao Yang ${ }^{1}$ and Christian Sanders ${ }^{5}$ \\ ${ }^{1}$ Ocean College, Zhejiang University, Zhoushan 316000, PR China \\ 2 National University of Singapore, Singapore, Singapore \\ 3 Xiamen University, Xiamen, PR China \\ ${ }^{4}$ The Third Institute of Oceanography, Xiamen, PR China \\ 5 Southern Cross University, Coffs Harbour, Australia \\ ${ }^{6}$ Key Laboratory of Marine Ecosystem Dynamics, Second Institute of Oceanography, Ministry of Natural Resources, Hangzhou, PR China.
}

Received 25 February 2020 / Accepted 5 August 2020

Handling Editor: Ziniu Yu

\begin{abstract}
Over $90 \%$ of the world's fisheries have been fully exploited or over-fished. Included is the large yellow croaker (Larimichthys crocea), an important commercial fish species in China whose population was nearly depleted prior to the 1980s. Although overfishing and natural resources collapse present a daunting issue, some studies indicate that improved management strategies could aid in natural stock restoration to prevent depletion. We developed an integrated assessment method grounded on an ecosystem-based approach and deigned an integrated index with three key aspects of habitat suitability, natural population status and government \& social interventions, to evaluate the potential restoration capacity of the species in a designated "national aquatic germplasm resource protected area" in Guanjinyang based on a data set spanning 1987 to 2015 . The results show that although restoration efforts on research and rehabilitation have increased greatly since late $1990 \mathrm{~s}$, the effectiveness stays moderate and the natural population remains near depletion.
\end{abstract}

Keywords: Restoration capacity / integrated assessment method / wild fish resources

\section{Introduction}

Substantial reduction of global fishery resources has been documented over the past half century with over $90 \%$ of the world's fisheries fully exploited or overfished. This includes $53 \%$ that have been fully exploited and $32 \%$ that have been overexploited, depleted, or are recovering from depletion (FAO, 2010). 29\% of fish and shellfish species have declined by as much as up to $90 \%$ (Worm et al., 2006). Several fish species have already been listed as extinct or endangered. Only $1 \%$ of the world's fish stocks are currently recovering from depletion (FAO, 2010).

China is the largest country for fishery production, export and consumption (Sun and Han, 2017; Sun and Li, 2018). It is responsible for most of the growth in fish availability, particularly from aquaculture, which accounts for more than

\footnotetext{
*Corresponding author: gqy@zju.edu.cn
}

$60 \%$ of global aquaculture production by weight (about 49.2 million tons of food-grade fish and 14.4 million tons of aquatic algae) in 2016 (FAO, 2018). However, the natural fishery resources, especially in the coastal and marine areas, have been declining rapidly. For instance, $36-53 \%$ of commercial species in $55-66 \%$ of exclusive economic zones were likely to be overfished from 1950 to 2004 (Srinivasan et al., 2010). A considerable amount of natural fishery resources has become extinct and many, including the large yellow croaker Larimichthys crocea (Richardson), are endangered.

The species is one of the most economically important marine fish in China. Its natural distribution spans the northern region of the South China Sea, the southern Yellow Sea, and the East China Sea. In the 1970s, wild catch of large yellow croaker in China is more than $1 \times 10^{5}$ tons per year, and reach $1.97 \times 10^{5}$ tons in 1974 (Xu and Liu, 2007; Zhang et al., 2017). In the Fujian sea area, the species migrates to Guanjingyang during mid-May to the end of June every year, which set the 
basis for the summer fishing seasons established before the 1960s. However, catch intensity increased substantially from the 1960 s to 1980 s, which led directly to its depletion (Zhang et al., 2017). The current market value of wild caught croaker ranges from $\$ 57.37$ per $\mathrm{kg}$ for individuals weighing about $150 \mathrm{~g}$ to $\$ 286.85$ per $\mathrm{kg}$ for those weighing over $1.5 \mathrm{~kg}$. Due to the high economic value and severe depletion, its restoration is both economically and ecologically important. The recovery of China's fishery resources requires cooperation within the country between local governments, relevant enterprises, fishermen and researchers. Marine ranching projects have been introduced as an important development component in the upgrading of the traditional fishing and aquaculture industries (Yang, 2016). Key restoration efforts, which include genetic research, marine protected area management, and release of larvae have increased substantially over the past 30 years. Restoration of the wild large yellow croaker population is important, with continuing work on ecosystem-based management efforts, local community involvement, monitoring of larvae release activities, investigation of life history traits, and construction of a germplasm repository.

The restoration of large yellow croaker in China is mainly led by the government, with the establishment of protected areas, no-fishing period, juvenile releasing, which has certain effects, but it is unknown if and when the wild population can be restored (Zhang et al., 2010, Ye, 2012, Zhang and Hong, 2015), many international restoration progresses of fishery resources are also difficult to evaluate (Neubauer et al., 2013). Thus in order to better assess the potential resilience of the species, we established an integrated assessment method grounded on an ecosystem-based approach. We applied our method on the designated "national aquatic germplasm resource protected area" of the large yellow croaker in Guanjingyang, Fujian, China, which could help us understand the possibility of increasing the natural stock back to recovery, and to provide a scientific basis for these recovery efforts. The assessment is based on available data from 1987 to 2015 .

\section{Materials and methods}

\subsection{Study area}

The $87 \mathrm{~km}^{2}$ Guanjingyang National Aquatic Germplasm Resource protected area (Fig. 1), formally established in 2007, is located at the southeastern part of Sansha Bay, Fujian Province. As the natural spawning ground of the large yellow croaker, it is also the first and only national aquatic germplasm resource protected area for the large yellow croaker. This region was earlier in 1985 designated as a protected area for large yellow croaker and restoration efforts were put into effect since then in response to depleting fisheries resources recent years (Fig. 2). To date, millions of dollars have been invested for the restoration of the natural population. Evaluating the effectiveness of restoration efforts made here could provide useful information for a wider management application to prevent depletion of large yellow croaker wild populations in China.

\subsection{Integrated assessment index}

From the perspective of ecosystem-based approach (Pikitch et al., 2004), the restoration potential of large yellow

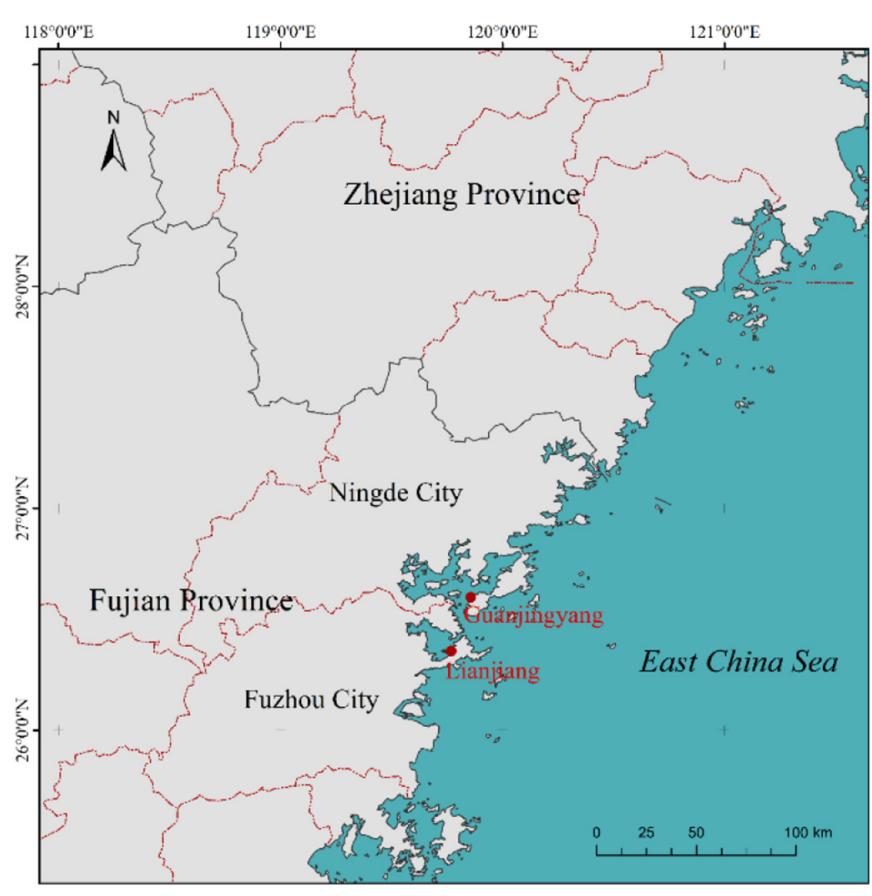

Fig. 1. Study area, the location of Guanjingyang.

croaker are determined not only by its own population, but also by the habitat as well as the social interventions. Thus to assess the restoration capacity of natural fishery resources, we developed an integrated index system (Tab. 1) which includes three key components: (1) habitat suitability (HS), which is the condition of a specific marine habitat where the croaker spends most of its life cycle; (2) natural population status (PS), which is the natural population size and genetic diversity; (3) government \& social interventions (GSI), which includes the key restoration efforts carried out by the government and community.

We call it the Restoration Capacity Index (RCI). Original data are transformed by extreme standardization, which is a linear method that puts all values in a range of $0-1$. In order to combine all the indicators together and show the overall restoration capacity trend, the entropy weighting method based on the variation of data is employed to calculate the weights of each indicator (Fagbote et al., 2014; Delgado and Romero, 2016; Zhao et al., 2018). Calculated weights of all indicators are listed in Table 1.

Weighting calculate:

(1) Data matrix: $\left(x_{i j}\right)_{m \times n}(i=1,2,3 \cdots m ; j=1,2,3 \cdots n)$

(2) Standardized data matrix:

Positive indicator:

$$
y_{i j}=\frac{x_{i j}-\min \left(x_{j}\right)}{\max \left(x_{j}\right)-\min \left(x_{i j}\right)}
$$

Negative indicator:

$$
y_{i j}=\frac{\max \left(x_{j}\right)-x_{i j}}{\max \left(x_{j}\right)-\min \left(x_{j}\right)}
$$




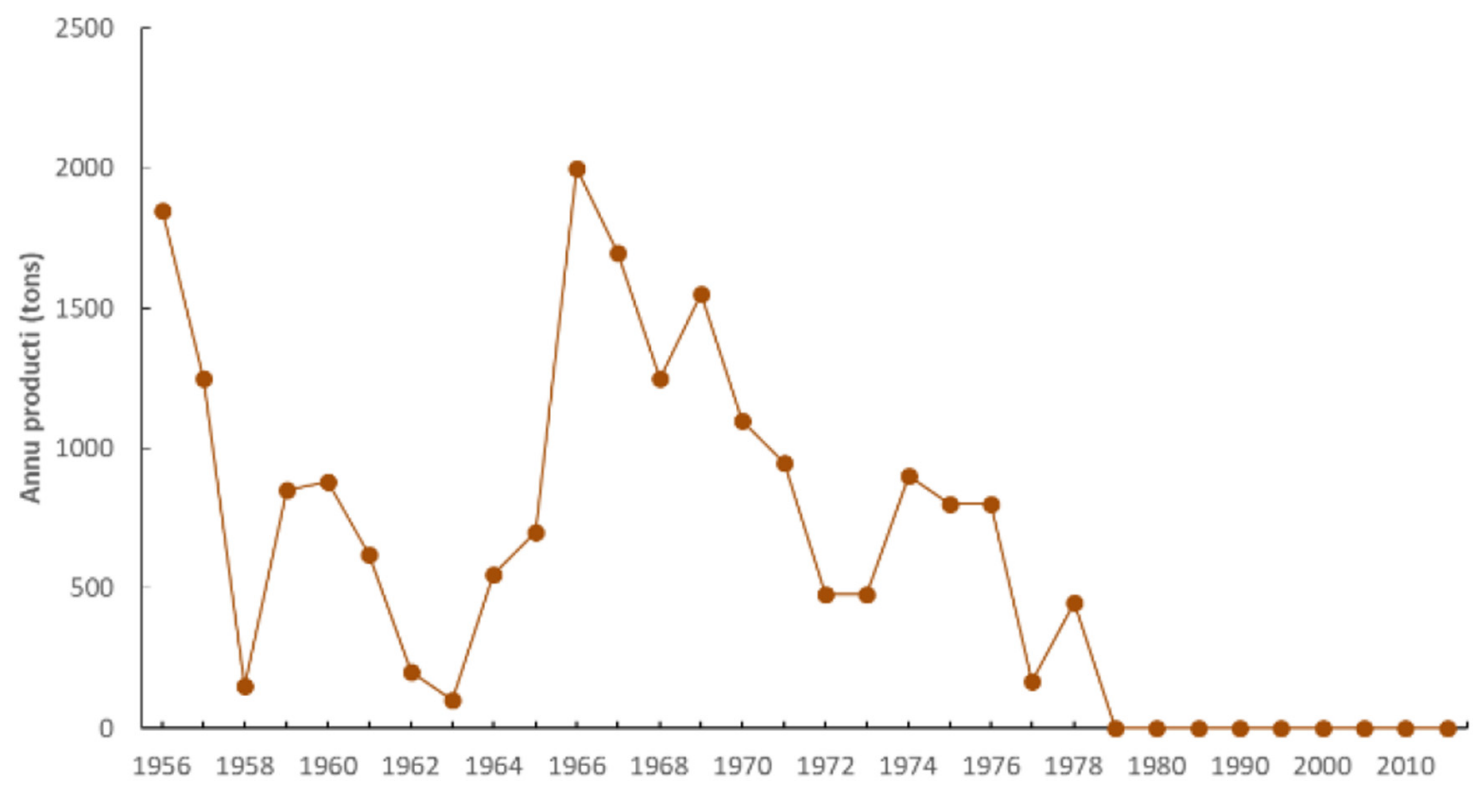

Fig. 2. Annual production of the large yellow croaker from 1956 to 2015 in Guanjingyang, China.

Table 1. Large yellow croaker evaluation index system and weight.

\begin{tabular}{llll}
\hline Component & Index & Indicators & Weight \\
\hline & Protected area & Protected area location, Protected area \\
& Water environment & Water temperature, & DO, \\
& & Salinity, & 0 \\
Habitat suitability (HS) & & pH & 0 \\
& Biodiversity & Shannon-weaver index & 0 \\
& Population size & Annual production & 0 \\
Natural population status (PS) & Genetic diversity & AFLP genetic diversity PIC \\
& Research input & Number of research institutes, Published research works & 0.07 \\
Government \& social interventions (GSI). & Rehabilitation efforts & Juvenile release number size & 0.07 \\
& Public awareness & Publicity activities \& Volunteers & 0.30 \\
\hline
\end{tabular}

(3) Calculate the entropy:

$$
\begin{gathered}
p_{i j}=-y_{i j} / \sum_{i=1}^{m} y_{i j} \\
k=\frac{1}{\ln m} \\
e_{j}=-k \sum_{i=1}^{m} p_{i j} \times \ln p_{i j}
\end{gathered}
$$

(4) Calculate the weight:

$$
w_{j}=\left(1-e_{j}\right) / \sum_{j=1}^{n}\left(1-e_{j}\right)
$$

The RCI is calculated by the three-dimensional state-space model (Mao et al., 2001; Wei et al., 2014; Jiang et al., 2017).
Thus, the capacity index can be considered the modulus of a three-dimensional space vector, which reflects the habitat development, population and interventions. The status of the RCI can be effectively depicted by calculating the modulus and the curvature:

$$
C_{j}=\sqrt{\sum_{i=1}^{n} x_{i j}^{2} w_{i}}
$$

where $C j$ is the evaluation index, $j$ represents different years, $w_{i}$ is the calculated weight by entropy method, $x_{i}$ indicates the standardized results, and $i$ represents the indicator types.

Evaluation of results is restricted to the values between 0 and 1 , where 0 means the worst and 1 presents the best. We further define different levels for the final results in this study: $0-0.29$ is the lowest level, $0.3-0.69$ indicates the medium level, 0.7-1.0 represents highest level. 


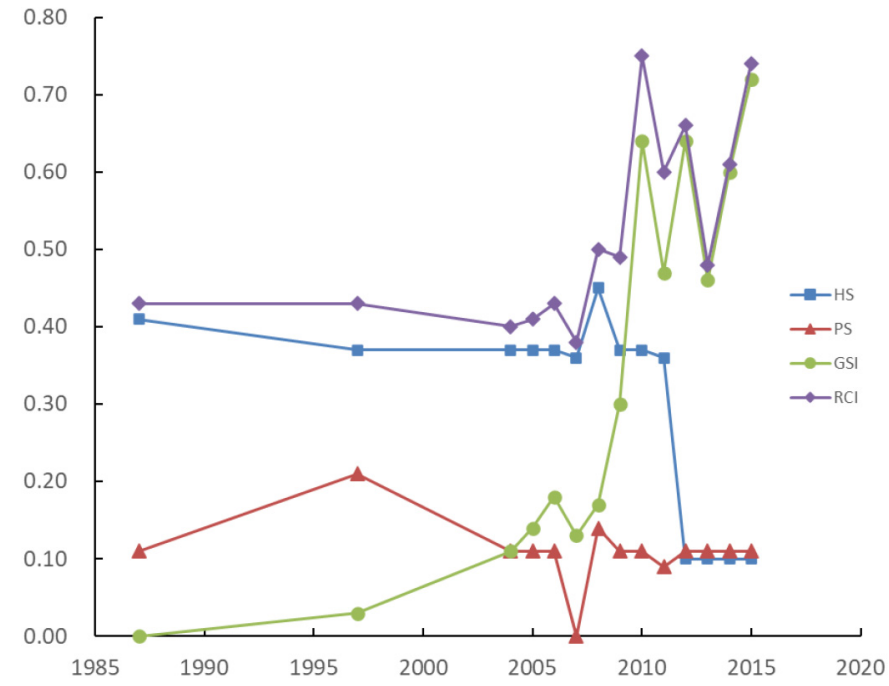

Fig. 3. The Restoration Capacity Index (RCI) of the restoration potential of wild large yellow croaker in Guanjingyang and the performance of Habitat Suitability (HS), Population Status (PS) and Government Social Interventions (GSI) from 1987 to 2015.

\section{Results}

\subsection{Habitat suitability (HS)}

The HS evaluation indicates that Guanjingyang habitat conditions stayed stable from 1987 to 2011, decreased in 2012 to 2015 (Fig. 3). Changes to the protected area are considered to be the most fluctuating component among all the indicators of HS, while water conditions and biodiversity changed little in the past decades.

None of the key physical and chemical factors for both living and reproduction fell outside of the survival ranges, and the key factors of water temperature, $\mathrm{DO}$, and $\mathrm{pH}$ mostly were within the optimal ranges. These indicators suggest no severe changes to the water environment, considered stable for the croaker in Guanjingyang.

\subsection{Natural population status (PS)}

The PS evaluation (Fig. 3) indicates relatively decrease from 2004 to 2015, in which get the lowest score at 2007. Specifically, population size has not increased, while population genetic diversity has fluctuated with time.

\subsection{Government and social Interventions (GSI)}

The GSI grew significantly in the Guanjingyang protected area (Fig. 3). It scored low in previous years from 1987 to 2008 , but increased quickly in the following years, arriving at its highest point in 2015. From 2010 to 2015, the scores fluctuated sharply. Specifically, research inputs and rehabilitation efforts in GSI rose dramatically from 2009, which became the key indicators.

\subsection{Integrated evaluation results}

The integrated results generally show an increase trend of the restoration capacity from medium level to the highest level (from 0.38 to 0.74 ) of large yellow croaker in Guanjingyang (Fig. 3). From 1987 to 2009, the values were lower than 0.5 due to overfishing and weak restoration efforts. The highest value was reached in 2010 and 2015 due to the increased number of large yellow croaker juveniles released in Guanjingyang and the growth of research input. This upward trend shows the government's commitment to the restoration of large yellow croaker resource since 2004. A sharp drop in 2013 is noted, which is likely due to the decrease of research input and juveniles released. However, the values increased sharply from 2014 to 2015 , related directly to an increase in released juveniles to reach the highest restoration capacity level in 2015.

The restoration capacity performance of HS, PS and GSI vary in scores and development trends (Fig. 3). The scores of HS and PS are more stable than GSI. While values of GSI show generally increasing trends overall, the scores of PS and HS have the opposite tendency. The integrated results are influenced mainly by HS (from 1987 to 2008), which is changed to GSI after 2009. While the integrated results increase these years the annual production still remains low. These results indicate that the habitat environment has not improved substantially and that the population and diversity of the large yellow croaker only changed slightly, despite the local government pouring a large amount of resources into restoration.

\section{Discussion}

The marine protected area in Guanjingyang was $329.5 \mathrm{~km}^{2}$ when established in 1985 . It was reduced to $314.7 \mathrm{~km}^{2}$ in 1997 because of the construction of a new port and further reduced to $190 \mathrm{~km}^{2}$ in 2012 due to the overall development of tourism, ports, and military purposes. The shrinkage of the area by $42.33 \%$ is considered as having a negative impact on the fish restoration efforts (Zhu, 2011).

Adult yellow croakers typically live in the mid-water zone of the near-shore area (depth less than $60 \mathrm{~m}$ ). The species is a warm-temperature migratory cluster fish in the North Pacific, with a water temperature range of $10-32^{\circ} \mathrm{C}$ and an optimum range of $18-25^{\circ} \mathrm{C}$. Water temperatures below $18^{\circ} \mathrm{C}$ or above $25^{\circ} \mathrm{C}$ are not suitable for the reproduction of large yellow croakers, hatching of fertilized eggs, or growth of juveniles. Additionally, the adaptation salinity range is $24.8-34.5 \%$ while the optimum range is 30.5-32.5\%o. Low salinity will affect cluster movements of the species. The suitable $\mathrm{pH}$ is 7.85-8.35, and the dissolved oxygen suitable for its survival is generally above $4 \mathrm{mg} / \mathrm{L}$ (Science and Technology Department of Fujian Province, 2004; Liu, 2013).

The recorded data for wild yellow croaker production in Guanjingyang goes back to 1956 (Fig. 2). The annual production underwent three major fluctuations since records began. In the late $1950 \mathrm{~s}$, because of large-scale "boatknocking" fishing activities (hitting interior of boat hull with a club sending sound waves through water to stun fish), fish production was reduced substantially in 1963 , less than $6 \%$ of 
G. Ye et al.: Aquat. Living Resour. 2020, 33, 24

Table 2. Genetic diversity evaluation results of Large Yellow Croaker (LYC) in different geographical groups by using AFLP.

\begin{tabular}{|c|c|c|c|c|c|}
\hline LYC & $\begin{array}{l}\text { Polymorphism } \\
\text { proportion (\%) }\end{array}$ & $\begin{array}{l}\text { Nei's genetic } \\
\text { diversity index }\end{array}$ & $\begin{array}{l}\text { Shannon-weaver } \\
\text { diversity index }\end{array}$ & Reference & $\begin{array}{l}\text { Sample } \\
\text { collection } \\
\text { year }\end{array}$ \\
\hline Wild LYC in Guanjingyang & 76.60 & 1 & 1 & Wang et al. (2002) & 1999 \\
\hline Cultured LYC in Guanjingyang & 57.50 & 0.12 & 0.18 & Lou et al. (2015) & 2011 \\
\hline Cultured LYC in Ningde & $69.20-70.60$ & 1 & 1 & Wang et al. (2002) & 1999 \\
\hline Cultured LYC in Ningde & 40.83 & 0.10 & 0.16 & Li et al. (2009) & 2007 \\
\hline Cultured LYC in Lianjiang & 40.53 & 0.10 & 0.16 & Li et al. (2009) & 2007 \\
\hline Wild LYC in Meizhou & 45.14 & 0.12 & 0.19 & Li et al. (2009) & 2007 \\
\hline Cultured LYC in Fujian & 63.11 & 0.21 & 0.32 & Liu et al. (2015) & 2008 \\
\hline Wild LYC in Daiqu & $40.47-54.62$ & 1 & 1 & Liu et al. (2005) & 2007 \\
\hline Wild LYC in Daiqu & 63.11 & 0.2 & 0.31 & Liu et al. (2015) & 2007 \\
\hline
\end{tabular}

Table 3. Some known commercial fishes' AFLP genetic diversity.

\begin{tabular}{lll}
\hline Species & $\begin{array}{l}\text { Polymorphism } \\
\text { proportion (\%) }\end{array}$ & Reference \\
\hline Epinephelus akaara & $18.40-47.70$ & Chen et al. (2008) \\
Nibea albiflora & $51.70-51.99$ & Han et al. (2006) \\
Pampus argenteus & $26.79-39.29$ & Meng et al. (2009) \\
Cynoglossus semilaevis & $40.20-49.80$ & Han et al. (2007) \\
Paralichthys olivaceus & $46.18-40.07$ & Zhang et al. (2004) \\
Larimichthys polyactis & $55.34-60.09$ & Lin et al. (2008) \\
Scomber japonicus & $57.75-64.59$ & Zhang et al. (2011) \\
\hline
\end{tabular}

that in 1956. With the ban on boat-knocking, the population recovered naturally in the following 5-10 years. In the late 1960 s, annual production increased to more than 1600 tons. However, it decreased again after 1970 due to the dramatic increase in fishing effort in the region. Since 1979, the natural production became severely depleted due to overfishing.

Genetic diversity is an important basis for evaluating the status of species resources, and is an important genetic indicator for measuring the evolutionary potential of a species' ability to withstand various survival stresses in nature. Many genetic diversity studies have shown that wild large yellow croaker populations have a relatively higher level of genetic diversity compared to cultured croakers (Wang et al., 2002; Li, 2009; Liu et al., 2015; Lou et al., 2015). By comparing the AFLP data of large yellow croaker with other known fish in Tables 2 and 3, it may be noted that the value of large yellow croaker is higher than that of most economically importance fish species in China. This parameter indicates that although the status of genetic resources of large yellow croaker has deteriorated sharply due to various reasons such as overfishing, genetic drift and artificial breeding, the current wild resource has a good evolutionary potential. This means that the large yellow croaker has the breeding potential for population recovery.

Since the 1950s, Chinese scholars have studied the diet, reproduction, population, ecology, nutritional and medicinal value along with the ethnic issue related to the large yellow croaker resource. The main results published before the late 1980s include: preliminary research on the ethnicity, sexual maturity characteristics, geographical structure variation and individual fertility of large yellow croaker, research on morphological characteristics of larvae and juveniles (Zhang et al., 2009; Jiang et al., 2014; Eero et al., 2012; Garcia and Rosenberg, 2010; Rosenberg et al., 2006; Worm and Zeller, 2009; Wu et al., 2014). These basic scientific works have actively promoted the progress of research, providing a scientific basis for the rational management and protection of the species.

Since the late 1980 s, research on wild large yellow croaker resources has focused on molecular biology, including the genome sequence and immune system(Costello and Lester, 2012; Wu et al., 2014). Han et al. (2015) analyzed the karyotype of Guanjingyang large yellow croaker. Wang et al. (2002) used isozyme, RAPD, AFLP and other analytical techniques to detect the genetic diversity of Guanjingyang wild large yellow croaker. Research on the genetic diversity and frozen semen preservation technology laid a solid scientific foundation for the restoration and preservation of wild large yellow croaker germplasm resources. In addition, the National 863 Project "Cultivation of High Quality and Stress Resistant Varieties of Large Yellow Croaker" was successfully completed in October 2010. The cultivation of excellent strains and the successful research on all-female egg production techniques have greatly alleviated the lack of breeding information related to the large yellow croaker. At the same time, the "National Large Yellow Croaker Genetic Breeding Center" was established in 2016 as the first national large yellow croaker genetic breeding center in China.

At present, Ningde City does not have a complete public participation system for the establishment and planning of protected areas and the protection of fishery resources. The Ningde City Ocean and Fisheries Bureau implemented government information disclosure on the Internet in May 2008, including institutional setup, administrative regulations, marine and fishery economic planning, basic statistical information on marine and fishery development, approval and implementation of major construction projects, etc. During 


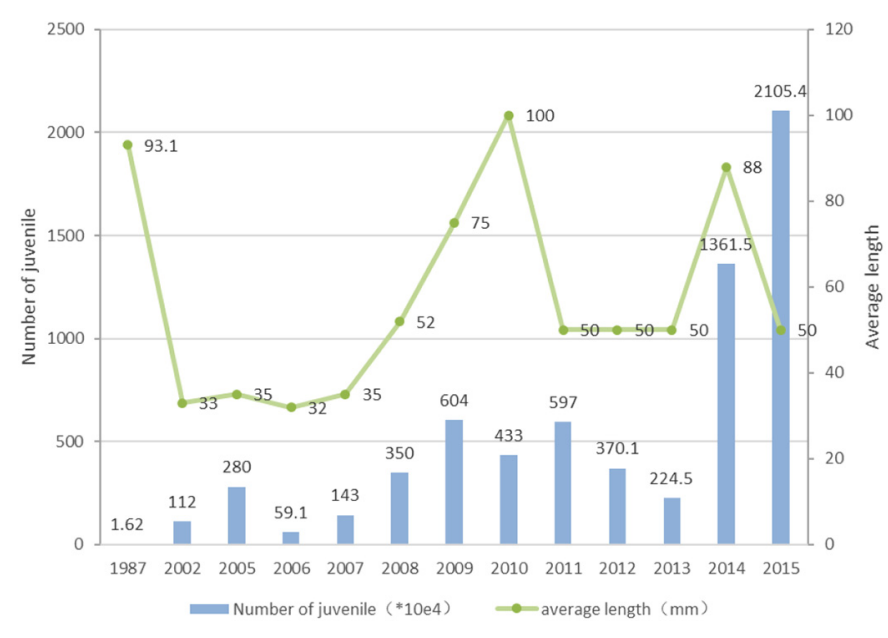

Fig. 4. Release of the large yellow croaker juvenile from 1987 to 2015 in Guanjingyang, China.

2008-2015, the Ningde government held annual notices or publicity activities on large yellow croaker protection, and actively cooperated with the restoration of the Guanjingyang large yellow croaker breeding reserve.

In addition, the Ningde Large Yellow Croaker Association was established in 2003. It is an industrial social group composed of the city's large yellow croaker industry and related units, community organizations and individual volunteers. However, the level of public participation in the protection of wild croaker resources is low, the government's advertising is weak, and local fishermen have little awareness of the recovery of wild large yellow croaker resources (Ningde Large Yellow Croaker Association, http://www.gjyfish.com/).

In order to strengthen the breeding and protection for the Guanjingyang large yellow croaker, Ningde City implemented navigational restrictions on the Guanjingyang large yellow croaker breeding protection zone during the migratory spawning period. Access is restricted $24 \mathrm{~h}$ a day specifically, from June 5th to 9th and June 19th to 23rd. During these periods, fry (more than $5 \mathrm{~cm}$ length) are released in the Guanjingyang breeding reserve (Fig. 4). From 2011 to 2015, the number of fry released was $4,3.701,2.245,13.615$, and 210.54 million, respectively. In 2016, 3.561 million fries of the species, cultivated by the national-level Guanjingyang large yellow croaker breeding center, were returned to the Guanjingyang large yellow croaker breeding protection zone. In the spring of 2019, the alliance of LYS seedling producers in Jiaocheng District of ningde city moved 1/3 (more than 1 billion) of LYC seedlings into Guanjingyang and Sandao sea area. In addition to human efforts such as proliferation and release, natural incidental factors may also affect the recovery of large yellow croaker. For example, Typhoon Saomai destroyed nearly 70000 cages in Fuding, Fujian at the summer of 2006; the juvenile that escaped into natural sea may help the restoration of wild stock.

However, many of the fish release have been caught before they have grown into adults and bred, which form an important cause of the fish stock cannot be restored. Prohibiting fishing for consecutive years (at least for several consecutive generations) may be an effective way to restore the natural population of large yellow croaker, as a result of the large yellow croaker in natural sea areas, artificial release and escape from the cage can grow into adults and breed offspring.

According to Ling et al. (2006) large yellow croaker resources in the East China Sea have been severely declining with no signs of recovery. Other fish such as the beltfish (Trichiurus haumela) and Chub mackerel (Scomber japonicus) are already in a state of decline with a possibility of extinction if left unprotected. The fishery resources in the Xiamen sea area and the Minjiang Estuary have also declined significantly, where the primary catch consists of young fish of low trophic levels (Huang et al., 2010a,b). Although the proliferation and release measures have achieved good results with high economic benefits in various places (Shen and Zhou, 2007; Zhang et al., 2009), unreasonable proliferation and release may bring various ecological risks to the natural resources and water ecosystems (Jiang et al., 2014). The impact on the local ecology from the proliferation and release of juveniles should therefore be taken into consideration, so that restoration of the large yellow croaker is effective.

In short, the limiting factor for the recovery of the large yellow croaker populations is overfishing. The uncontrolled knocking operations used by the fishermen in the 1960 s devastated the large yellow croaker population in the study region. The intensity of fishing in the 1980s depleted large yellow croaker stock. In general, to obtain better recoveries, a breakthrough in capture yield must be achieved.

\section{Conclusions}

Comparing the existing assessments of fishery recovery potential (Kapetsky, 2000; Davies and Jonsen, 2011; Isomaa et al., 2013), this study is the first known attempt to synthesize three key dimensions to evaluate the restoration capacity of marine fish resources. This assessment not only considers attributes of the natural population of the fish species, but also the habitat quality as well as the related government and social interventions. We highlight that the restoration efforts put by the government, scientists and local society are the key drivers for endangered species recovery (Zheng et al., 2013; Hildebrandt et al., 2018), which have only been suggested by other studies.

In Guanjingyang's case, restoration efforts have increased greatly since 2007, including the increase of research inputs, rehabilitation efforts and public awareness, all of which could have positive effects on promoting the recovery of large yellow croaker resource (Xu, 2009; Ma, 2016), but at this point still have had no significant influence for its natural stock recovery. Similarly, a reserve area was designated in 1987 as a result of the severe depletion. Even with the conservation efforts, which have been in effect for almost 30 years, the natural population remained near extinction in 2015. Although the genetic diversity of the species in Guanjingyang was a little higher than other areas, for example, Ningde, Lianjiang (Tab. 2), and may indicate better potential recovery (Neel, 2008; Shao et al., 2009), the integrated evaluation results pointed to a low possibility of natural stock recovery. The main hindrance for the recovery of the large yellow croaker may be related to the low proliferation capacity due to near extinction of the species (Zhang et al., 2017). However, some researchers indicate that 
extensive studies on genes, species, population, community and ecosystem combined with the efforts on natural habitat restoration may facilitate the restoration of the large yellow croaker wild fisheries in the future (Yan, 2019). China is currently vigorously promoting the development of marine ranching to ensure food safety and improve human health. These efforts also provide opportunities for the restoration of wild fishery stocks, with so far 110 national marine ranches built and distributed along the coast of the Bohai Sea, the Yellow Sea, the East China Sea and the South China Sea. Although fishery restoration efforts have reached unprecedented levels, the evidence suggests that after the depletion of resources, it could be extremely difficult to restore its natural stock. This study highlights that conservation is much more important than restoration for the sustainability of marine biological resources.

Acknowledgements. This research was supported by science and technology project of Zhejiang Province (2017C25004) from Zhejiang Province, China, Key Projects of Philosophy and Social Sciences Research, Ministry of Education (18JZD059) and Ministry of Science and Technology (2019YFD0901305). The data was supported by Fujian Provincial Department of Ocean and Fisheries, China. and thanks to the Observation and Research Station of Marine Ecosystem in the Yangtze River Delta, Ministry of Natural Resources.

\section{References}

Chen S, Liu T, Li Z, Gao T. 2008. Genetic population structuring and demographic history of red spotted grouper (Epinephelus akaara) in South and East China Sea. Afr. J. Biotechnol. 7: 3554-3562.

Costello C, Lester SE. 2012. Status and solutions for the world's unassessed fisheries. Science 338: 517-520.

Davies TD, Jonsen ID. 2011. Identifying nonproportionality of fishery-independent survey data to estimate population trends and assess recovery potential for cusk (Brosme brosme). Can. J. Fish. Aquat. Sci. 68: 413-425.

Delgado A, Romero I. 2016. Environmental conflict analysis using an integrated grey clustering and entropy-weight method: a case study of a mining project in Peru. Environ. Model. Softw. 77: $108-121$.

Eero M, Vinther M, Haslob H, Huwer B, Casini M, Storr-Paulsen M, Köster FW. 2012. Spatial management of marine resources can enhance the recovery of predators and avoid local depletion of forage fish. Conserv. Lett. 5: 486-492.

Fagbote EO, Olanipekun EO, Uyi HS. 2014. Water quality index of the ground water of bitumen deposit impacted farm settlements using entropy weighted method. Int. J. Environ. Sci. Technol. 11: $127-138$.

FAO (Food and Agriculture Organization). State of World Fisheries and Aquaculture (SOFIA)-SOFIA 2010, FAO Fisheries Department, Rome, 2010.

FAO (Food and Agriculture Organization). State of World Fisheries and Aquaculture 2018, FAO Fisheries Department, Rome, 2018.

Garcia SM, Rosenberg AA. 2010. Food security and marine capture fisheries: characteristics, trends, drivers and future perspectives. Philos. Trans. R. Soc. London 365: 2869-2880.

Han ZQ. 2006. Analysis of genetic diversity of Nibea albiflora by AFLP markers. J. Fish. China 30: 640-646 (in Chinese).
Han ZQ, Zhuang ZM, Gao TX, Liu JX, Li YH, Wang ZY, Tang QS. 2007. Genetic diversity in Cynoglossus semilaevis by AFLP, RAPD and mtDNA markers. J. Fish. Sci. China 14: 192-200 (in Chinese)

Han Z, Xu H, Shui B, Zhou Y, Gao T. 2015. Lack of genetic structure in endangered large yellow croaker Larimichthys crocea from China inferred from mitochondrial control region sequence data. Biochem. Syst. Ecol. 61: 1-7.

Hildebrandt TB, Hermes R, Colleoni S, Diecke S, Holtze S, Renfree MB, Stejskal J, Hayashi K, Drukker M, Loi P, Göritz F, Lazzari G, Galli C. 2018. Embryos and embryonic stem cells from the white rhinoceros. Nat. Commun. 9: 1-9.

Huang LM, Xie YJ, Zhang YZ, Li J, Liu QD. 2010a. Current fisheries resources assessment in Xiamen coastal waters. J. Jimei Univ. (Natural Science) 15: 81-87 (in Chinese).

Huang LM, Li J, Zhang YZ, Xie YJ. 2010b. Current fishery resource assessment in the MinJiang River Estuary and its neighboring waters. J. Trop. Oceanogr. 29: 142-148 (in Chinese).

Isomaa M, Kaitala V, Laakso J. 2013. Baltic cod (Gadus morhua callarias) recovery potential under different environment and fishery scenarios. Ecol. Model. 266: 118-125.

Jiang YZ, Lin N, Yang LL. 2014. The ecological risk of stock enhancement and the measures for prevention and control. J. Fish. Sci. China 21: 413-422 (in Chinese).

Jiang D, Chen Z, Dai G. 2017. Evaluation of the carrying capacity of marine industrial parks: a case study in China. Mar. Policy 77: 111-119.

Kapetsky MD. 2000. Present applications and future needs of meteorological and climatological data in inland fisheries and aquaculture. Agric. For. Meteorol. 103: 109-117.

Li Z, Fang X, Chen J, Chang J, Lei G, Zhang G, Zhao B, Wang Z. 2009. Loss of the genetic diversity in cultivated populations of Pseudosciaena crocea by AFLP. Oceanol. Limnol. Sin. 40: 446-450 (in Chinese).

Lin LS, Chen J, Li HY. 2008. The fishery biology of Trichiurus japonicus and Larimichthys polyactis in the East China Sea region. Mar. Fish. 2: 126-134.

Ling J, Li S, Yan L. 2006. Analysis on the utilization of main fishery resources in the East China Sea. Mar. Fish. 28: 111-116 (in Chinese).

Liu JF. Culture and biology of large yellow croaker, Xiamen University Press ( in Chinese), China, 2013.

Liu B, Dong W, Wang Y, Zhu S, Wu W. 2005. Identification of Germ Plasm in Pseudosciaena Crocea Tai-chu Race by AFLP. Acta Hydrobiol. Sin. 29: 413-416 (in Chinese).

Liu Y, Wu XW, Wu XF, Xue LY, Xiao SJ, Wang ZY. 2015. Analysis of genetic diversity in cultured populations of DaiQu and Min-Yue Groups of Larimichthys crocea. J. Southwest University (Nat. Sci.) 37: 6-12 (in Chinese).

Lou JF, Lei SY, Zhu JQ, Wu XF. 2015. AFLP Analysis of genetic diversity in two cultured communities of Pseudosciaena crocea. Adv. Mar. Sci. 33: 361-366 (in Chinese).

Mao HY, Yu DL. 2001. Regional carrying capacity in Bohai Rim. Acta Hydrobiol. Sin. 56: 363-371 (in Chinese).

Ma X. Releasing enhancement of Large Yellow Croaker (Larimichthys crocea) in Dongtou sea water and its effect evaluation, Masters thesis, Zhejiang Ocean University, 2016 (in Chinese).

Meng YY, Zhang LZ, Zhao F, Shi ZH, Zhuang P. 2009. Preliminary study on the genetic diversity of four geographic populations of silver pomfret (Pampus argenteus). Mar. Fish. 31: 48-52 (in Chinese).

Neel MC. 2008. Patch connectivity and genetic diversity conservation in the federally endangered and narrowly endemic plant species Astragalus albens(fabaceae). Biol. Conserv. 141: 0-955. 
Neubauer P, Jensen OP, Hutchings JA, Baum JK. 2013. Resilience and recovery of overexploited marine populations. Science 340: 347-349.

Pikitch EK, Santora C, Babcock EA, Bakun A, Sainsbury KJ. 2004. Ecosystem-based fishery management. Science 305: 346-347.

Rosenberg AA, Swasey JH, Bowman M. 2006. Rebuilding US fisheries: progress and problems. Front. Ecol. Environ. 4: 303-308.

Shao JW, Chen WL, Peng YQ, Zhu GP, Zhang XP. 2009. Genetic diversity within and among populations of the endangered and endemic species Primula merrilliana in China. Biochem. Syst. Ecol. 37: 699-706.

Shen XQ, Zhou YD. 2007. Enhancing release and effect assessment of fisheries resource in the Yangtze River Estuary and Hangzhou Bay. Fish. Modern. 34: 54-57 (in Chinese).

Srinivasan UT, Cheung WW, Watson R, Sumaila UR. 2010. Food security implications of global marine catch losses due to overfishing. J. Bioecon. 12: 183-200.

Sun L, Han X. China fisheries yearbook 2017, China Agriculture Press ( in Chinese), China, 2017.

Sun L, Li SM. China fisheries yearbook 2018, China Agriculture Press (in Chinese), China, 2018.

Wang Z, Wang Y, Lin L, Qiu S, Okamoto N. 2002. Genetic polymorphisms in wild and cultured large yellow croaker Pseudosciaena crocea using AFLP fingerprinting. J. Fish. Sci. China 9: 198-202 (in Chinese).

Wei C, Guo Z, Wu J, Ye S. 2014. Constructing an assessment indices system to analyze integrated regional carrying capacity in the coastal zones-a case in Nantong. Ocean Coastal Manag. 93: $51-59$.

Worm B, Barbier EB, Beaumont N, Duffy JE, Folke C, Halpern BS, Sala E. 2006. Impacts of biodiversity loss on ocean ecosystem services. Science 314: 787-790.

Worm B, Zeller D. 2009. Rebuilding global fisheries. Science 325: $578-585$.

Wu C, Zhang D, Kan M, Lv Z, Zhu A, Su Y, Jiang L. 2014. The draft genome of the large yellow croaker reveals well-developed innate immunity. Nat. Commun. 5: 5227-5227.
Xu KD, Liu ZF. 2007. The current stock of large yellow croaker Pseudosciaena crocea in the east China sea with respects of its stock decline. J. Dalian Fish. Univ. 22: 392-396.

$\mathrm{Xu}$ Y. 2009. Fujian Province's fishery proliferation and release have achieved good results. Mod. Fish. Inf. 24: 32-32 (in Chinese).

Yan X. 2019. Accelerate the reconstruction of wild large yellow croaker resources in the East China Sea. Guangming Daily. 2019-10-06(006) ( in Chinese).

Yang HS. 2016. Construction of marine ranching in China: reviews and prospects. J. Fish. China 40: 1133-1140 (in Chinese).

Zhang Q, Xu X, Qi J, Wang X, Bao Z. 2004. The genetic diversity of wild and farmed Japanese flounder populations. J. Ocean. University. China (NatSci) 34: 816-820 (in Chinese).

Zhang XM, Wang XJ, Tu Z, Zhang PD, Wang YZ, Gao TX, Wang SJ. 2009. Current status and prospect of fisheries resource enhancement in Shandong Province. Chin. Fish. Econ. 27: 51-58 (in Chinese).

Zhang LY, Su YQ, Ding SX, Niu SF, Liu DT, Wang J. 2010. Analysis of genetic diversity of Decapterus maruadsi in the coastal waters of Fujian Province. J. Fish. China 34: 680-687 (in Chinese).

Zhang QY, Hong WS. 2015. Resource status and remediation strategy for large yellow croaker in Guanjingyang Bay. Mar. Fish. 37: 179-186 (in Chinese)

Zhang QY, Hong WS, Chen SX. 2017. Stock changes and resource protection of the large yellow croaker (Larimichthys crocea) and ribbon fish (Trichiurus japonicus) in coastal waters of China. J. Appl. Oceanogr. 36: 438-445 (in Chinese).

Zhao J, Ji G, Tian Y, Chen Y, Wang Z. 2018. Environmental vulnerability assessment for mainland China based on entropy method. Ecol. Indica. 91: 410-422.

Zheng YJ, et al. 2013. Review and prospects for resource biology of main marine demersal food fishes along the coastal waters of China. J. Fish. China 37: 151-160 (in Chinese).

Zhu M. 2011. Preliminary review report on the "Amendment of the Regulations on the Administration of Guanjingyang Large Yellow Croaker Breeding Protection Area (Draft)". Standing Committee of Fujian Provincial People's Congress Fujian. (in Chinese).

Cite this article as: Ye G, Lin Y, Feng C, Chou LM, Jiang Q, Ma P, Yang S, Shi X, Chen M, Yang X, Sanders C. 2020. Could the wild population of Large Yellow Croaker Larimichthys crocea (Richardson) in China be restored? A case study in Guanjingyang, Fujian, China. Aquat. Living Resour. 33: 24 